\title{
ESTATUTO DO DESARMAMENTO: UM ESTUDO DE CASO A PARTIR DE EUGEN EHRLICH E HANS KELSEN
}

\author{
José Raul Cubas Júnior ${ }^{1}$ \\ Demetrius Nichele Macei $^{2}$
}

\begin{abstract}
RESUMO: O objetivo do artigo é analisar um caso concreto - sentença judicial - à luz dos pressupostos de validade da norma jurídica em Eugen Ehrlich e Hans Kelsen, o vitalismo e o normativismo jurídico, respectivamente. Para tanto, o método utilizado é o hipotéticodedutivo, com pesquisa bibliográfica e documental, em especial as obras "Fundamentos da Sociologia do Direito" e "Teoria Pura do Direito", encerrando com análise de caso concreto, representado por sentença judicial prolatada em processo criminal. A principal conclusão alcançada destaca a possibilidade de harmonizar, na análise de validade de uma mesma norma jurídica, as teorias tratadas no estudo.
\end{abstract}

Palavras-chave: Estatuto do Desarmamento; Norma; Validade; Ehrlich; Kelsen.

\section{DISARMAMENT STATUTE: A CASE STUDY AS OF EUGEN EHRLICH AND HANS KELSEN}

\begin{abstract}
The objective of the article is to analyze a concrete case - judicial sentence - in light of the validity assumptions of the legal norm in Eugen Ehrlich and Hans Kelsen, vitalism and legal normativism, respectively. The method used is the hypothetical-deductive, with bibliographical and documentary research, especially the works "Fundamentals of Sociology of Law" and "Pure Theory of Law", closing with analysis of concrete case, represented by judicial sentence prosecuted in criminal proceedings. The main conclusion reached highlights the possibility of harmonizing, in the analysis of the validity of a same legal norm, the theories treated in the study.
\end{abstract}

Keywords: Disarmament Statute; Norm; Validity; Ehrlich; Kelsen.

\footnotetext{
1 Mestrando em Direito Empresarial e Especialista em Direito Tributário e Processual Tributário, ambos pelo Centro Universitário Curitiba - UNICURITIBA. Rua Simão Bolivar, nº 526, Juvevê, Curitiba/PR, CEP 80040140. E-mail: cubasjunior@gmail.com

2 Doutor em Direito Tributário pela Pontifícia Universidade Católica de São Paulo - PUCSP. Professor no Programa de Pós-Graduação Stricto Sensu em Direito do PPGD/UNICURITIBA. Rua Chile, no 1.678, Rebouças, Curitiba/PR, CEP 80220-181. E-mail: demetrius@ macei.com.br
} 


\section{INTRODUÇÃO}

O presente artigo busca, inicialmente, estabelecer os pressupostos de validade da norma jurídica pela teoria do Direito Vivo, exposta na obra "Fundamentos da Sociologia do Direito" de Eugen Ehrlich, em contraposição ao normativismo jurídico, delineado na "Teoria Pura do Direito" de Hans Kelsen. Destas considerações iniciais são extraídos elementos que conduzirão a análise de um caso concreto, qual seja uma norma jurídica expedida por autoridade judicial que, por ocasião da prolação de sentença, absolveu indiciados pela prática de porte ilegal de arma de fogo.

O tema da pesquisa é a validade da norma, delimitado pela investigação de validade de uma norma jurídica [sentença - caso concreto] à luz do Direito Vivo e do normativismo jurídico, cuja problemática subsume-se em averiguar a possibilidade de harmonizar, na mesma norma jurídica, a existência simultânea dos pressupostos de ambas as teorias.

Para tanto, é utilizado o método hipotético-dedutivo, partindo-se de pesquisa bibliográfica, com base nas obras "Fundamentos da Sociologia do Direito" (EHRLICH, 1986) e "Teoria Pura do Direito" (KELSEN, 2009), de artigos publicados em periódicos científicos e em anais de eventos, e finalizando com pesquisa documental para cotejo do caso concreto.

A estrutura do artigo contempla divisão em cinco seções, incluindo esta introdução.

Nas duas seções seguintes são expostas as teorias desenvolvidas por cada autor, mais precisamente o Direito Vivo e o normativismo jurídico, respectivamente.

A quarta seção é dedicada ao estudo do caso concreto, da análise da validade da norma jurídica - sentença - à luz dos pressupostos obtidos a partir do estudo desenvolvido nas seções anteriores.

$\mathrm{Na}$ última seção são apresentados, resumidamente, os resultados obtidos com pesquisa e a sua conclusão.

\section{EUGEN EHRLICH E O DIREITO VIVO}

Eugen Ehrlich [1862-1922], jurista e sociólogo austríaco, dedicou-se ao estudo da sociologia do direito como a verdadeira ciência do direito. Entre as suas principais obras, destaca-se "Grundlegung der Soziologie des Rechts" [Fundamentos da Sociologia do Direito], publicada originalmente em $1913^{3}$, em que sustenta a Sociologia do Direito como a ciência do

3 Em sua $3^{\text {a }}$ edição a obra foi republicada no ano de 1967, da qual partiu a tradução para o português, por René Ernani Gertz, em 1986.

Rev. de Argumentação e Hermeneutica Jurídica | e-ISSN: 2526-0103 | Porto Alegre | v. 4 | n. 2 | p. 59 - 79 | Jul/Dez. 2018 
direito, porque este não é estático e deve levar em consideração as mutações pelas quais passa a sociedade (SPAREMBERGER, 2003, p. 119-120).

Ao considerar as relações que se desenvolvem entre os homens no seio de dada sociedade e os fenômenos sociais que delas derivam [e não apenas as regras prescritas pelo direito posto], Ehrlich desenvolveu a chamada "Teoria do Direito Vivo", uma construção teórica decorrente das respostas que obteve quanto ao autoquestionamento sobre "de onde surgem as regras jurídicas, quem lhes dá vida e eficiência” (EHRLICH, 1986, p. 16)?

Segundo o autor, grande parte do direito não tem sua origem no Estado e boa parte não é por ele criada (EHRLICH, 1986, p. 16). Assim, para Ehrlich, a lei positivada, produto da tarefa do legislador, não é e nem pode ser tida como origem do direito.

O agir humano não encontra vinculação direta a ameaça de coação oficial imposta pelos tribunais. Pelo contrário, considera que o homem sempre está submetido à coação psicológica localizada fora do campo do direito, decorrente das relações estabelecidas pelo regramento social [e não legal] no qual está inserido (EHRLICH, 1986, p. 23).

Por vezes, nas relações estabelecidas com seus pares, o homem se vê compelido ao cumprimento de suas obrigações como curso natural da ordem imposta pela comunidade, pelas associações das quais faz parte, pelo costume, sendo que a "ordem na sociedade humana se apoia no fato de que obrigações jurídicas em geral são cumpridas, não no fato de que podem ser levadas a juízo" (EHRLICH, 1986, p. 16), porque maior do que a ameaça de coação estatal é o receio dos reflexos negativos [v.g. reprovação social] que de certa conduta se possa resultar.

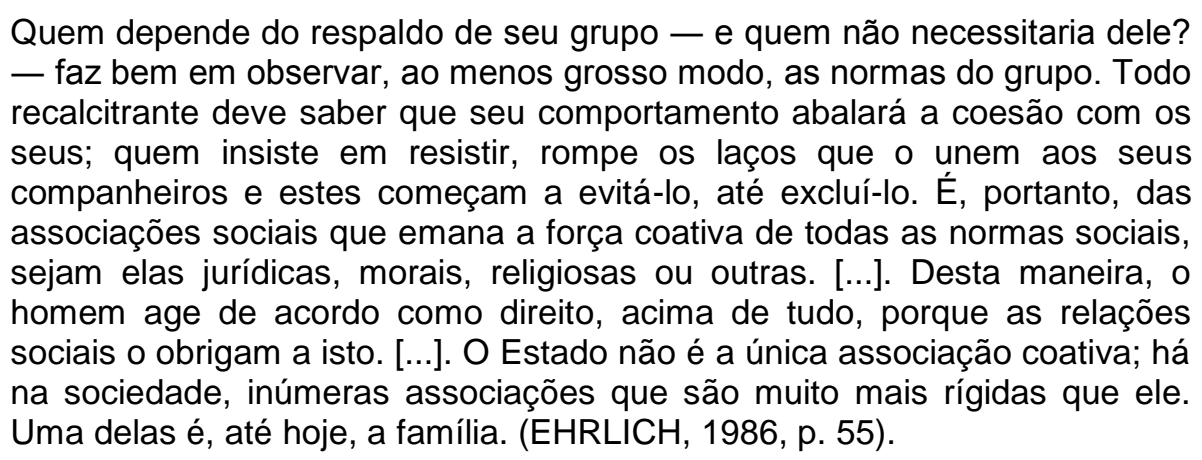

Comunidade, organização ou associação podem ser a família, a igreja, o clube, o ambiente de trabalho e tantas outras quanto possíveis, que se caracterizam por formar um conjunto de pessoas que, ao se relacionarem mutuamente, não só reconhecem determinadas regras como decisivas para seu agir em geral, como, de fato, agem em sua conformidade. Essas regras, das mais variadas formas [regras do direito, da religião, da moral, do costume, 
da honra, do bom comportamento, entre outras], formam a realidade social e devem ser analisadas no contexto em que são vigentes (EHRLICH, 1986, p. 37).

Ao considerar a sociologia do direito como a doutrina científica do direito, Ehrlich (1986, p. 23) afirma que, como qualquer ciência social, ela tem suas bases no conceito de sociedade humana, caracterizada pelo conjunto de organizações de tipos bem diversificados e que estão em constante interação. As relações que se desencadeiam nessas organizações são reguladas pelo direito, esse tido não como prescrição jurídica [produto da positivação], mas como ordem jurídica interna e independente do direito legislado.

Em outras palavras, Ehrlich separou normas jurídicas de prescrições jurídicas. Estas, quando instituídas só passam à condição de normas jurídicas no momento em que são aceitas, observadas, cumpridas pela sociedade. Até lá são apenas prescrições jurídicas.

As normas jurídicas não reclamam positivação. Existem em maior número que prescrições jurídicas, porque estas derivam daquelas e não o contrário. Seja qual for a sociedade, “[...] há muito mais normas jurídicas que prescrições jurídicas, porque sempre há mais direito para condições específicas que para condições similares e também existe mais direito do que os juristas tomam conhecimento, quando procuram fixá-lo em palavras" (EHRLICH, 1986, p. 36).

Para Ehrlich (apud MOREIRA, 2013, p. 235) o estudo da ciência jurídica não se completa com a mera análise das normas aplicadas pelos juízes, porquanto o homem, no seu dia-a-dia, não conduz sua conduta para observância do direito estatal, mas para não violar as regras do agir humano, do costume, aquilo que voluntariamente obedece e respeita.

Assim, a força que impulsiona o agir do homem, o cumprimento das ordens previstas no direito positivado [prescrições jurídicas], em normas jurídicas não escritas ou mesmo naquelas decorrentes da moral, costumes, tradições e tantas outras previstas na sociedade têm substancial importância para a ciência jurídica.

Equivale dizer, a ciência jurídica reclama a análise do direito que se desenvolve no seio da sociedade, que advém das relações estabelecidas entre os indivíduos e que estão em constante mutação, pois "o direito estatal, em todos os sentidos significativos, apenas acompanha a evolução social" (EHRLICH, 1986, p. 122) e ainda assim de maneira lenta.

O direito posto "não reproduz o quadro mais pálido daquilo que realmente acontece na vida" (EHRLICH, 1986, p. 377). Assim, a ciência jurídica e a evolução do conhecimento jurídico clamam pela análise daquilo que Ehrlich denominou Direito Vivo, aquele que, "oriundo das organizações sociais" (VIEIRA, 2015, p. 110), "trata das regras que 
efetivamente são reconhecidas e praticadas nas relações sociais em cada localidade, cultura e período histórico" (MOREIRA, 2013, p. 225), que "independentemente do Direito legislado [...] domina a vida" (SPAREMBERGER, 2003, p. 121).

Nesse contexto, para encontrar a norma válida e eficaz em determinada comunidade [quaisquer organizações sociais], é necessário partir de induções, pois também "a sociologia, incluindo aí a sociologia do direito, deve ser uma ciência da observação" (EHRLICH, 1986, p. 362). Ao cientista jurídico cumpre "conhecer e descrever o concreto e não o abstrato, os fatos, não as palavras e, portanto, tem por objeto não somente o direito 'válido para os tribunais e órgãos de autoridade', mas também, e especialmente, o direito vigente que, 'não formulado em proporções jurídicas', regula toda a vida social" (TREVES, 2004, p.120 apud SGARBOSSA, 2016, p. 171).

Para Ehrlich " [...] a maior parte do direito origina-se imediatamente da sociedade, sendo a regulação jurídica formal posterior, pelo que a norma jurídica seria condicionada pela sociedade, aplicável se e na medida em que observe seus pressupostos sociais" (2004, p. 121 apud SBARGOSSA, 2016, p. 171).

O Direito Vivo não se limita ao conteúdo de um documento. Não cabe ao jurista se aprisionar em códigos, nos diplomas legais. Seu material de trabalho não se subsume a lei posta, mas se encontra “[...] nas relações jurídicas propriamente ditas, nos documentos jurídicos, no Direito como ele é, como ele se dá” (SPAREMBERGER, 2003, p. 121).

Em outras palavras, o Direito Vivo não é aquele posto pelos tribunais ou pelo legislador, mas é vivido, observado pelo homem, decorre do agir humano no dia-a-dia e é cumprido independentemente de coação estatal (EHRLICH, 1986, p. 378).

Ou seja, a norma jurídica, vigente e eficaz em determinada organização social, quando pelo trabalho do legislador for prescrita em lei, se torna prescrição jurídica, de tal maneira que, nesse caso, a sua origem não será o Estado, pois, a despeito dela ainda não ter sido positivada, já era vigente e eficaz independentemente de qualquer coação estatal (VIEIRA, 2015, p. 124).

Em síntese, na teoria desenvolvida por Ehrlich, fundada na sociologia, o direito não se aprisiona nos códigos, não se resume em mera prescrição jurídica ou no chamado direito legislado/positivado. Ao contrário, surge do agir humano, cuja eficácia pode ser aferida todos os dias e independe da coerção estatal, pois "Direito Vivo no conteúdo de um documento não é aquilo que os tribunais no caso de uma disputa jurídica declaram como obrigatório, mas somente aquilo que as partes, na vida real, de fato observam” (EHRLICH, 1986, p. 381). 
Assim, é no Direito Vivo que Ehrlich encontrou as respostas para indagações ${ }^{4}$ antes citadas. Normas não se confundem com prescrições jurídicas, não precisam de positivação, previsão expressa em lei, surgem da sociedade, das relações estabelecidas entre os homens, cujos regramentos são aceitos, observados e cumpridos (eficácia) mais em decorrência de uma coação que se encontra fora do campo do direito do que da ameaça de uma coação estatal oficial prevista em lei e decorrente da técnica legislativa. (EHRLICH, 1986, p. 55).

Nas palavras de Sgarbossa (2016, p. 171), Ehrlich "escapa à visão estatalista e reducionista do jurídico". Na investigação, pesquisa e produção do conhecimento jurídico não se nega a necessidade do estudo da jurisprudência, do direito posto, mas se exige que o verdadeiro jurista [e porque não especialmente o julgador] também tenha os olhos voltados para as ações humanas derivadas com naturalidade da vida em sociedade: "O método sociológico, portanto, exige que os resultados obtidos a partir das decisões dos órgãos estatais sejam complementados pela observação direta da vida" (EHRLICH, 1986, p. 379).

\section{HANS KELSEN E O NORMATIVISMO JURÍDICO}

Hans Kelsen [1881-1973], jurista e filósofo austríaco, dedicou-se à construção de um método científico para o conhecimento jurídico que fosse livre de ideologias, destacando-se entre suas obras a "Teoria Pura do Direito" e a "Teoria Geral das Normas".

Para Kelsen (2009, p. 79) a conduta humana importa apenas a partir do momento em que estabelecida no conteúdo da norma, ou seja, positivada.

A ciência jurídica é uma ciência normativa, porquanto toma a norma como seu objeto. Significa afirmar que se está no plano do dever "porque a norma pode ser conceituada como o sentido de um ato por meio do qual uma conduta é prescrita, permitida ou facultada [...]" (SPAREMBERGER, 2003, p. 118).

O normativismo sustentado por Kelsen reclama entender que proposições jurídicas não se confundem com normas jurídicas, tal como ciência jurídica se distingue de direito. Proposição jurídica, como produto da ciência jurídica, tem por escopo descrever, enunciar o Direito prescrito nas normas jurídicas. Em outras palavras, proposição jurídica se distingue da norma jurídica tal como se distingue a função do conhecimento jurídico da função da autoridade jurídica. Nas palavras de Cunha (2008, p. 281):

A norma jurídica seria um imperativo posto pela autoridade competente, um comando por ela estabelecido, uma permissão, ou ainda uma atribuição de

4 “De onde surgem as regras jurídicas, quem lhes dá vida e eficiência?” (EHRLICH, 1986, p. 16) 
competência. Ainda que se tenha em mente que tais imperativos sejam expressos por meio de fórmulas lingüísticas, certo é que não se trata de um mero enunciado, uma mera proposição, mas de um comando, de um ato produtor do Direito, seja ele um ato posto pelo legislador, pela Administração Pública, seja pelo juiz [...].

Por sua vez, a proposição jurídica é um enunciado formulado pela Ciência do Direito visando à descrição do seu objeto. Portanto, trata-se de uma distinção qualitativa (prescrição/descrição), em que a norma jurídica é um ato da autoridade que produz o Direito e a proposição jurídica, um juízo hipotético da ciência jurídica que descreve o sistema posto, [...].

As proposições normativas formuladas pela ciência jurídica descrevem o direito e não atribuem quaisquer deveres ou direitos e, por isso, podem ser verídicas ou inverídicas. Já, as normas de dever, porquanto atribuem deveres e direitos aos sujeitos jurídicos, só podem ser consideradas válidas ou inválidas (KELSEN, 2009, p. 82).

As proposições representam juízos enunciativos de determinado objeto posto ao seu conhecimento, tal como o faz, por exemplo, um tratado de direito civil ou de qualquer outra área do direito. Não há um comando e sua confirmação se situa no campo da veracidade.

A norma jurídica, por não representar um enunciado (descrição), mas um comando [prescrição], apenas pode ser válida ou inválida. Será válida se seguiu o regramento legal de sua elaboração, pois é de uma norma superior que extrai seu fundamento de validade.

O direito tido como ciência normativa se difere das outras ciências que buscam o conhecimento pela "lei da causalidade, de processos reais". As leis naturais demandam o estabelecimento da relação entre causa e efeito [causalidade]. As proposições jurídicas são orientadas por outro princípio, qual seja o da imputação (KELSEN, 2009, p. 84-87).

Kelsen assim descreve (2009, p. 87): "Na proposição jurídica não se diz, como na lei natural, que, quando A é, então B é, mas que, quando A é, B então deve ser, mesmo quando B porventura efetivamente não o seja". O autor traz, ainda, outro elemento para distinguir causalidade de imputação, conforme assevera Cunha (2008, p. 283):

Uma outra distinção apontada por Kelsen (1999) é que, na relação de causalidade, os elos que unem os eventos se desdobram em uma cadeia infinita, ou seja, a conseqüência produzida por uma determinada causa é, por sua vez, causa produtora de outro evento e assim sucessivamente. Da mesma forma, se percorrermos esse trajeto em sentido inverso, a causa de um determinado evento é, por sua vez, conseqüência provocada por uma causa mais remota e assim sucessivamente. Com o princípio da imputação, tal não ocorre, já que a regra de "causação" é fruto da vontade humana, pelo que a série de imputação é limitada, existe um ponto terminal.

Causalidade revela uma cadeia infinita, relações de causas e efeitos sucessivos. 
Toda "causa concreta pressupõe, como efeito, uma outra causa, e todo efeito concreto deve ser considerado como causa de um outro efeito, por tal forma que a cadeia de causa e efeito [...] é interminável nos dois sentidos” (KELSEN, 2009, p. 101).

Diferentemente da natureza, orientada pela causalidade, o "número de elos de uma série putativa não é, como o número de elos de uma série causal, ilimitado, mas limitado" (KELSEN, 2009, p. 101).

Ocorre que, se a série putativa [diferentemente da causalidade] é finita, como a validade de uma norma seria dada por uma que lhe é superior e assim sucessivamente?

Porquanto possa parecer contraditória a asserção acima [de que a norma jurídica sempre retira seu fundamento de validade de uma norma superior e ainda assim se orienta pelo princípio da imputação - série finita] de fato não o é. Conforme explica Cunha (2008, p. 283), o sistema normativo também pressupõe um limite, o qual foi dado por Kelsen ao recorrer à chamada "norma fundamental" como aquela que garante unidade ao sistema, uma norma que não é mais posta, mas pressuposta e que garante validade a todo o sistema

Direito é ciência normativa. Embora a norma retire seu fundamento de validade de uma norma que lhe é superior [e esta de outra que hierarquicamente superior a ela também o seja] não haverá cadeia infinita, pois ao sistema é dada a validade por uma norma superior a todas, a chamada norma fundamental: "Como a norma fundamental é o fundamento de validade de todas as normas pertencentes a uma mesma ordem jurídica, ela constitui a unidade na pluralidade destas normas" (KELSEN, 1999, p. 228 apud CUNHA, 2008, p. 284).

Nas palavras de Baracho (1979, p. 39), a norma fundamental não representa uma norma do direito positivo. Antes pelo contrário, é "pressuposta pela Ciência do Direito", de tal maneira que a "ordem jurídica é um sistema de normas que estão ligadas entre si, pelo fato de a criação de toda e qualquer norma que pertence a este sistema ser determinada por outra norma do mesmo sistema, e, em última etapa, pela norma fundamental”.

Como assevera Carlotti (2015, p. 2.290), a norma fundamental é aquela hierarquicamente superior a todas, a garantia de validade de todo o ordenamento jurídico.

A Teoria Pura do Direito é doutrina avalorativa e normatista, pois "se propõem a descrever o próprio objeto e não a lhe atribuir um entendimento tido por melhor que outros, propondo-se a fazer ciência e não se apresentando como uma filosofia, um credo, uma ética", devendo ser entendido "como próprio objeto somente o direito positivamente existente, especialmente o direito que assumiu a forma da lei [...]" (LOSANO, 2014, p. 32). 
Considerando o direito ciência normativa, em que a norma não representa um juízo descritivo, mas prescritivo, a ciência do direito não deve trabalhar com a observação daquilo que não está positivado. As externalidades [v.g. o agir humano, o comportamento dos indivíduos, valores morais ou éticos], conforme Kelsen, não importam para a ciência jurídica.

\section{EHRLICH X KELSEN: DIREITO VIVO X NORMATIVISMO JURÍDICO}

Ao sustentar a sociologia do direito como a ciência do direito, porque este não é estático e deve observar as mutações pelas quais passa a sociedade (SPAREMBERGER, 2003, p. 119-120), Ehrlich se opôs ao normativismo jurídico e sofreu severas críticas de Hans Kelsen, “[...] que afirmou ocorrer um sincretismo metodológico, decorrente da confusão estabelecida por Ehrlich entre ser e dever-ser" (SPAREMBERGER, 2003, p. 116).

Como afirma Castro (2016, p. 53-54), em Kelsen o objeto da ciência do direito é a norma jurídica, sendo que a realidade social e econômica só poderá interessar à ciência do direito quando estiver prescrita, ou seja, não deve se preocupar com a análise da realidade, dos fatos como eles acontecem. Diferentemente, para Ehrlich a ciência do direito deve se valer da observação, das experiências empíricas, da forma como o homem se comporta na sociedade, mesmo porque esses fatos importam na validade das normas.

A relevância dada por Ehrlich é retratada por Carlotti. Analisar o comportamento das pessoas em dada sociedade, a maneira como cumprem ou não as normas estabelecidas [lembrando que para Ehrlich norma jurídica não se confunde com prescrição jurídica - esta representa a positivação da primeira] o fazia se opor ao "direito estatal que parecia criar um mundo alternativo ou um mundo ideal de 'deveres' que não correspondia aos comportamentos regulares observáveis quase que empiricamente” (CARLOTTI, 2015, p. 2.293).

Em Kelsen "a ciência do direito opera por deduções a partir de um objeto ideal, resultado de uma operação intelectual: a norma jurídica". A ciência do direito, para Ehrlich é descritiva e indutiva; para Kelsen é normativa e dedutiva (CASTRO, 2016, p. 53-54).

Ao tratar da pureza axiológica proposta e defendida por Kelsen, Larenz (1997, p. 93 apud SPAREMBERGER, 2003, p. 117-118) afirma, resumidamente, que a ciência do direito “[...] não tem a ver com a conduta efectiva do homem, mas com o prescrito juridicamente. Não é, pois, uma ciência de fatos, como a sociologia, mas uma ciência de normas; o seu objeto não é o que é ou o que acontece, mas sim um complexo de normas”.

Purificar a ciência do direito foi o objetivo de Kelsen na obra "Teoria Pura do Direito", em que a depurou "de qualquer elemento estranho ao seu objeto" (CUNHA, 2008, p. 
280), "uma pureza epistemológica (corte que exclui da ciência jurídica qualquer objeto a ela estranho) e também uma pureza valorativa (corte axiológico)" (CUNHA, 2008, p. 282).

Nas palavras de Kelsen (2009, p. 118), a ciência do direito, como ciência, "não se considera obrigada senão a conceber o Direito positivo de acordo com a sua própria essência e a compreendê-lo através de uma análise da sua estrutura", sendo que a Teoria Pura do Direito, por surgir em forte contradição com a ciência jurídica tradicional, revestida de um caráter ideológico, revela-se "[...] como verdadeira ciência do Direito”.

Ao resumir os pressupostos em que se fundam a Teoria Pura e o Direito Vivo, Carlotti (2015, p. 2.288) destaca que a "pureza proposta por Kelsen é uma delimitação da atividade de descrição do direito [...]", sendo que Ehrlich se permite "descrever a realidade social tendo objeto de estudo regularidades de comportamento e abstrair, a partir destes comportamentos observados, regras que comporiam o direito 'vivo' [...]".

Oposto ao que se vê em Ehrlich, a sociologia como ciência do direito e a necessidade da observação empírica do comportamento humano, em Kelsen o "direito seria um conjunto de regras abstratas que se determinam mutuamente e, portanto, não teria nenhum tipo de correspondência com a realidade empírica, nem com comportamentos regulares observáveis" (CARLOTTI, 2015, p. 2.291).

Se de um lado o Direito Vivo não se limita ao texto legislado, positivado, mas que pode ser encontrado pela observação empírica do comportamento humano, do agir das pessoas independentemente da ameaça de coação estatal e que, por isso, permite reconhecer a existência de normas não prescritas, mas observadas/cumpridas; de outro o normativismo jurídico, depurado de quaisquer ideologias, dita uma ciência do direito cujo conhecimento se limita à análise de sua própria estrutura em busca de desvendar seu objeto.

De acordo com as teorias desenvolvidas por cada autor [Ehrlich e Kelsen], acima resumidamente expostas, o desafio que se apresenta conduz à problemática do presente artigo, qual seja a existência de matrizes opostas para a conformação de validade da norma jurídica: Haveria a possibilidade de uma norma jurídica [aqui entendida como comando normativo] ser válida, simultaneamente, à luz do Direito Vivo e do normativismo jurídico, a despeito dos pressupostos destes se fundarem em argumentos aparentemente antagônicos? 


\section{PORTE ILEGAL DE ARMA DE FOGO: UM ESTUDO DE CASO}

Se no Direito Vivo a validade da norma jurídica depende da observação do agir humano, daquilo que o homem respeita por imposição da comunidade, dos costumes, entre outros, e não em decorrência de prescrições jurídicas [direito positivado], para o normativismo jurídico, livre de valores axiológicos, depurado de ideologias, sua conformação de validade se dá pela verificação de conformidade da lei com aquela que lhe é superior e, assim, sucessivamente, até chegar à norma fundamental, aquela que não é posta, mas pressuposta e que garante validade e unidade a todo o sistema jurídico.

Em busca de identificar casos em que, eventualmente, ambas as teorias possam coexistir e seus fundamentos garantirem [sem se anularem], simultaneamente, a conformação de validade de uma mesma norma, é que se elegeu um caso concreto sobre o qual se volta à análise desenvolvida nesta pesquisa.

Em 02 de junho de 2015 o Ministério Público Estadual de Santa Catarina ofertou, perante a Vara Criminal da Comarca de Joaçaba/SC, denúncia contra M.A.R., Y.V.Z., E.C.R. e F.S.M. pela prática do crime de "porte ilegal de arma de fogo", tipificado no artigo 14 da Lei Ordinária $\mathrm{n}^{\circ}$ 10.826, de 22 de dezembro de 2003 [Estatuto do Desarmamento], conforme Ação Penal nº 0001455-21.2015.8.24.0037.

Recebida a denúncia pelo magistrado, Juiz de Direito Márcio Umberto Bragaglia, os autos tiveram regular curso processual, encerrando a prestação jurisdicional com a sentença de absolvição datada de 16 de janeiro de 2018 [da qual não recorreu o Ministério Público], na qual o magistrado expôs não apenas as razões de seu convencimento para o caso concreto, mas também os fundamentos por ele utilizados para interpretar os dispositivos legais insertos no Estatuto do Desarmamento [notadamente o porte ilegal de arma de fogo], de tal maneira que a absolvição se impõe quando presentes os seguintes requisitos:

[...] a) a mínima ofensividade da conduta do agente; b) nenhuma periculosidade social (e real) da ação; c) o reduzidíssimo grau de reprovabilidade do comportamento; d) a inexpressividade da lesão jurídica comprovada e, ainda, e) circunstâncias pessoais do agente e da apreensão do armamento que não indiquem a finalidade efetivamente criminosa. (SANTA CATARINA, 2017, p. 346-347)

Equivale dizer, a despeito de comprovada autoria e materialidade, afasta-se a tipicidade da conduta, porque esta deve ser analisada sob os aspectos formal e material, sendo o primeiro a pura e simples subsunção do fato ao dispositivo legal e, a segunda, a ameaça ou lesão a "bem jurídico de forma inadmissível” (SANTA CATARINA, 2017, p. 345). 
Ocorre que, os fundamentos colacionados na sentença, quanto à análise da tipicidade da conduta, revelam que, no caso concreto, a validade da norma [expedida pela autoridade judicial - sentença] pode ser confirmada a partir de conceitos extraídos da Teoria do Direito Vivo [de Ehrlich] ao tempo em que, embora possa parecer antagônico, também pela Teoria Pura do Direito [normativismo jurídico de Kelsen]. Mais que isso, a validade, nesse caso, poderia ser aferida individualmente, filiando-se em cada teoria, mas também simultaneamente por ambas, sem que uma anulasse a outra.

Para o Direito Vivo, a validade da norma deve ser confirmada a partir da observação do agir humano. Diferentemente da prescrição jurídica, do texto positivado, a norma jurídica reclama aceitação no seio da comunidade. O homem cumpre a norma não por ameaça de coação estatal, mas porque sua observância é tida por obrigatória perante a comunidade, porque não se pode exigir dele conduta diversa.

Já, para o normativismo jurídico referido na Teoria Pura do Direito, livre de valores axiológicos, a norma será válida quando observados os requisitos de sua criação, a nominada pirâmide de Kelsen, em que a norma inferior retira seu fundamento de validade de uma norma que lhe é superior, até chegar à norma fundamental.

\subsection{A VALIDADE DA NORMA - SENTENÇA - PELA TEORIA DO DIREITO VIVO}

A primeira conformação de validade, que se pode extrair da sentença aqui analisada [norma jurídica], encontra-se nas lições de Ehrlich, conforme se pode observar na seguinte passagem: "Assim, é possível dizer que somente serão materialmente típicas aquelas condutas que afetarem de maneira substancial valores tidos como essenciais por determinada sociedade.” (SANTA CATARINA, 2017, p. 346)

A observação do dia-a-dia, da forma como o homem se comporta na sociedade e os motivos que o faz agir assim aparecem em vários trechos da norma jurídica [sempre é bom lembrar que o termo aqui utilizado se refere ao caso concreto analisado, porque, ao tempo que o documento jurídico é denominado sentença, veicula uma norma jurídica que, no caso, é produzida pela autoridade judicial], como se verifica da elucubração acerca dos reflexos do Estatuto do Desarmamento na contemporaneidade:

[...] percebe-se do dia-a-dia forense que a política desarmamentista do governo brasileiro, iniciada no ano de 1997, brutalmente fortalecida no ano de 2003 e continuamente difundida, não tem auxiliado na diminuição da violência, que cresce a cada ano, pois parece já bastante óbvio que o necessário é desarmar e prender criminosos perigosos, desarticular cartéis de tráfico de entorpecentes e reprimir com rigor os crimes contra a vida, e 
não dificultar a posse pacífica de armas de fogo para a defesa da vida, da família e da propriedade, por trabalhadores, homens e mulheres de bem, que é o que, lamentavelmente, tem sido feito na prática. (SANTA CATARINA, 2017, p. 346)

Para além da observação pela autoridade jurídica [juiz], a norma traz elementos que indicam a observação do agir humano também pelos demais "atores" envolvidos no processo judicial, como consignou o magistrado, ao esclarecer que a postura por ele adotada também é acompanhada, naquela Comarca, pelo Ministério Público e autoridades policiais, que realizam "verdadeiro exercício de equidade perante o caso concreto" (SANTA CATARINA, 2017, p. 347), a ponto de invocar ensinamentos de Aristóteles e S. Tomás de Aquino: "se emergir um caso em que a observância da lei seja danosa ao proveito comum, não deve ela ser observada". (apud SANTA CATARINA, 2017, p. 347)

A passagem inserta na sentença, acima citada, revela, tal como em Ehrlich, a diferença entre a prescrição jurídica [lei] e norma jurídica. Da sentença, como produto do trabalho do magistrado, extrai-se a norma jurídica, cuja validade pode ser verificada a partir da sua conformação com o agir humano. Em outras palavras, a norma jurídica expedida pelo magistrado encontra sua validade se, a despeito de sua inconformidade com o texto da lei, for aceita e cumprida pelo homem, pois não se pode exigir do seu destinatário algo para além daquilo que ele possa cumprir.

Em outras palavras, se o Direito Natural, diversamente do Direito Positivo, orienta-se pelo princípio da causalidade [se A, então B], não pode a autoridade expedir norma jurídica para impor um comando diverso daquele cuja conduta se possa exigir do destinatário, nesse sentido é que o magistrado, para fundar a expedição da norma jurídica [sentença] invocou, nas palavras de Barbuy, novamente lições de S. Tomás de Aquino:

\begin{abstract}
A lei escrita, assim como não dá força ao direito natural, assim não lhe pode diminuir nem tirar a força, pois, não pode a vontade do homem mudar-lhe a natureza. E, portanto, se a lei escrita contiver alguma disposição contrária ao direito natural, será injusta, nem tem força para obrigar. Pois o direito positivo se aplica quanto ao direito natural não importa que se proceda de um ou de outro modo, [...]. E, por isso, tais leis escritas não se chamam leis, mas, antes, corrupções da lei, [...]. E, portanto, não se deve julgar de acordo com elas. (BARBUY apud SANTA CATARINA, 2017, p. 347-348)
\end{abstract}

De acordo com a Teoria do Direito Vivo, na sentença há o reconhecimento da força motriz dos costumes e a impossibilidade de sobrepujar o Direito Natural por aquele legislado: "Aliás, o direito natural à legítima defesa substancial, um daqueles mais afetados pelo Estatuto do Desarmamento, também sempre foi reconhecido pelas tradições humanas mais 
diversas, constituindo parte do Cânone jurídico da humanidade há muito." (SANTA CATARINA, 2017, p. 348)

Como em Ehrlich, para quem o direito não se aprisiona em códigos, no caso aqui analisado a norma jurídica expedida revela substancial valorização dos costumes, tradições e demais elementos que impulsionam o agir humano e que só podem ser extraídos a partir da observação do dia-a-dia, tal como fez o magistrado ao considerar a necessidade e a intenção não ilícita dos acusados quanto ao emprego das armas apreendidas, a vida pregressa, os costumes da comunidade local, a realidade social em que inseridos:

[...] aqueles que residem ou laboram em locais distantes e desabitados, como em sítios e fazendas, estão, em virtude da política desarmamentista, tão ou mais suscetíveis à criminalidade do que os também desprotegidos habitantes dos centros urbanos, [...]. Ademais, é incontestável que a atuação dos órgãos policiais para garantir a segurança destes indivíduos é dificultada frente a distância que devem percorrer para chegar aos locais, o que deixa, muitas vezes, os moradores rurais à total mercê de bandidos, considerando que o Estado retirou destes cidadãos o direito primordial e inerente ao ser humano de legítima defesa, não suprindo-lhes esta necessidade (o que seria não apenas impertinente como impossível). Diante disso e para garantir tal direito, diversos moradores rurais optam por possuir armas de fogo em desacordo com as determinações legais, desrespeitando uma legislação que tolhe seus direitos naturais e em nada lhes assiste. (SANTA CATARINA, 2017, p. 351-352)

Conforme assinalado anteriormente, para encontrar a norma válida e eficaz em determinada comunidade [quaisquer organizações sociais], é necessário partir de induções. Pela Teoria do Direito Vivo ao cientista jurídico cumpre "conhecer e descrever o concreto e não o abstrato, os fatos, não as palavras e, portanto, tem por objeto não somente o direito 'válido para os tribunais e órgãos de autoridade', mas também, e especialmente, o direito vigente que, 'não formulado em proporções jurídicas', regula toda a vida social” (TREVES, 2004, p.120 apud SGARBOSSA, 2016, p. 171).

Nesse sentido, os fundamentos lançados na sentença encontram amparo jurídico nos pressupostos estabelecidos pela Teoria do Direito Vivo. Veja-se, por exemplo, o seguinte cotejo realizado, pela autoridade judicial, entre o caso concreto e a conduta tida por correta naquela comunidade local, na qual os fatos ocorreram:

Atendendo ao requisito de reduzidíssimo grau de reprovabilidade do comportamento, cito como razões adicionais de decidir as recentes moções de repúdio ao Estatuto do Desarmamento aprovadas pelas Câmaras de Vereadores dos municípios de Joaçaba e Água Doce (SC), demonstrando que, em termos regionais, a conduta dos réus possuí baixíssimo grau de reprovabilidade, com embasamento na posição local quanto à política desarmamentista. As pessoas da comunidade estão fartas de serem tratadas como ovelhas rumo ao abatedouro, nas mãos de um Estado 
opressor e mentiroso, que as desarmou injustamente e sob os mais farsantes pretextos. O Poder Judiciário, que, como os demais poderes da República, também emana do povo (CF, Art. 1ำ, Parágrafo Único) e em seu nome em seu favor deve ser exercido, não pode ser fazer surdo ao clamor popular que, em especial nesta região sob minha jurisdição, tem sido mais que um mero ruído disforme e inconstante, mas, ao contrário, um brado público firme, justo, digno, um reclame de homens e mulheres corajosos, que querem ser os responsáveis por suas vidas, segurança e destinos. (SANTA CATARINA, 2017, p. 353)

A importância dada ao destinatário da prestação jurisdicional, como se vê na sentença, porquanto se funda na necessidade da interpretação mais justa da lei em razão da realidade social e dos comandos Constitucionais, justifica-se na medida em que, como assevera Cubas Júnior e Teixeira (2017, p. 74), “A atividade judicante, à medida que se limita ao mundo dos juristas, deixa de lado a essência de sua existência, o povo."

A norma jurídica [sentença] expedida pela autoridade judicial, se acaso submetida ao crivo de um juízo de validade, fundar-se-ia, pela Teoria do Direito Vivo, na adequação de seu comando com o agir humano, elemento extraído a partir da observação do dia-a-dia, do concreto e não do abstrato, das ações humanas derivadas da vida em sociedade e que, das quais, não se pode exigir comportamento diverso, ainda que sob o pretexto, estritamente positivista, de que a conduta estaria tipificada em Lei [Estatuto do Desarmamento].

Nesse contexto, a argumentação lançada na sentença parece ter evitado que o magistrado, em sua atividade judicante, recaísse em um dos principais problemas do juiz tradicional, a "estrita subordinação à figura do legislador, vez que este é uma figura mítica, distante das massas e próximo dos grupos economicamente determinantes". (CUBAS JÚNIOR; TEIXEIRA, 2017, p. 59).

Assim, no caso concreto, a validade da norma [comando inserto na sentença] à luz do Direito Vivo se funda na assertiva de que, embora aparentemente tipificada a conduta do porte ilegal de arma de fogo [leia-se sem a respectiva autorização], a sentença de absolvição prolatada pelo magistrado, motivada pelo cotejo entre a ação humana [submetida à análise] e a realidade social em que praticada, encerra norma jurídica da qual não deriva comando contrário ao comportamento minimamente exigível na comunidade.

A Teoria do Direito Vivo, conhecido ou não pela autoridade judicial por ocasião da prolação da sentença em comento, nutre, alimenta e confirma a validade da norma que dela nasce e ingressa no mundo jurídico. Embora ausente respectivo referencial direto, os pressupostos dados pela citada teoria aparecem e motivam a sentença, validando a norma expedida. Contudo, em seguida, é possível verificar que na construção do comando 
normativo, sua validade também pode ser objeto de aferição pelo normativismo jurídico, descrito na Teoria Pura do Direito, de Kelsen, razão pela qual não se acredita na adoção inconsciente, pela autoridade judicial, dos pressupostos dados pela teoria do Direito Vivo.

\subsection{A VALIDADE DA NORMA - SENTENÇA - PELO NORMATIVISMO JURÍDICO}

Em Kelsen, como já tratado anteriormente, o direito é tido como ciência normativa. É válida a norma jurídica que, para seu ingresso no mundo jurídico, seguiu os procedimentos legais para a sua expedição [v.g. expedida pela autoridade competente], conquanto retire seu fundamento de validade de uma norma que lhe é superior, a conhecida pirâmide de Kelsen, em que ao sistema jurídico é dada a validade e unidade, em última análise, pela chamada norma fundamental, aquela que, embora não escrita, lança luz sobre todo o sistema e orienta principiologicamente todas as demais.

Pela teoria pura do direito, livre de valores axiológicos, para o direito não importa a conduta humana que não esteja contida na norma.

Nesse sentido, como se passará a observar, mesmo na hipótese de se eliminar da sentença [sob análise] todos os fundamentos consignados pela autoridade judicial, que validam a norma pela teoria do Direito Vivo, ainda assim a sua conformação de validade restaria incólume, se não pelo Direito Vivo, pelo normativismo jurídico [Teoria Pura do Direito], razão pela qual se acredita na adoção, consciente, pela autoridade judicial, dos pressupostos dados pela teoria do Direito Vivo, e não meramente consignados - ao acaso - na sentença.

Explica-se: após consignar elementos que denotam a observação do agir humano, da forma como o homem se comporta na sociedade, os costumes locais, entre outros, que demandariam reconhecer a ausência de tipicidade para o caso, a autoridade judicial [responsável para prolação da sentença], no exercício do seu legítimo poder judicante [autoridade competente], passou a fundamentar a norma [a sentença] em dispositivos dados pelo Texto Constitucional, notadamente em princípios Constitucionais, como se pode observar na seguinte passagem:

Assim, visando salvaguardar direitos maiores e mais relevantes, a tônica que venho adotando ao julgar fatos similares ao em tela tem sido a correção da absurda e iníqua norma que penaliza aquela pessoa decente que pretende, com a arma de fogo, garantir os próprios (e daqueles que o cercam) direitos fundamentais à vida, segurança, propriedade e, porque não dizer, dignidade da pessoa humana (artigos 1으. III, e 5ㅇ, caput, da Constituição Federal), frente às barbaridades que o cidadão pode estar sujeito ao ser subjugado por criminosos. (SANTA CATARINA, 2017, p. 348) 
Para conferir validade à norma por ela expedida [comando derivado da sentença], a autoridade judicial se valeu de interpretação de acordo com o Texto Constitucional, subsumiu os fatos ao disposto na letra da Lei Ordinária [Estatuto do Desarmamento], interpretando-a de tal maneira que pudesse dar a ela um alcance balizado pelos valores encartados na própria Constituição Federal [o que não se confunde com a admissão de valores axiológicos], harmonizando a legislação infraconstitucional “[...] em especial com os direitos fundamentais à vida, à liberdade, à segurança e ao bem estar [...]” (SANTA CATARINA, 2017, p. 359).

Ao tomar como pressupostos alguns princípios constitucionais [v.g. direito vida], definiu-se o alcance da Lei Ordinária [Estatuto do Desarmamento] aos casos em que não se vislumbra, da sua aplicação, a violação de garantias fundamentais.

Conforme argumentos expostos no caso em questão, se o Texto Constitucional garante o direito à vida, não pode a Lei Ordinária, que por óbvio é hierarquicamente inferior, proibir que o cidadão defenda a sua vida, pois “[...] ainda é possível interpretarmos as formalidades legais impostas por leis e normas iníquas sob a luz da Constituição e do Direito Natural, universal por definição e inalienável de todo homem, de defender sua vida, sua família e sua propriedade." (SANTA CATARINA, 2017, p. 357)

Neste contexto, a aplicação irrestrita do Estatuto do Desarmamento, a depender do caso concreto, como cita o magistrado, seria “[...] incompatível com os princípios que ela própria (a Lei) deveria, em tese, proteger, com violação, inclusive, de preceitos maiores, constitucionais, e mesmo de direito natural.” (SANTA CATARINA, 2017, p. 353-354)

Assim, também pelo normativismo jurídico, a validade da norma expedida restaria confirmada, porquanto do Texto Constitucional é que retira seu fundamento de validade, inclusive porque na sentença há indicação expressa no sentido de que "[...] a todos os Juízes, em seus níveis de atuação, competência e jurisdição, é atribuída a missão de analisar o caso concreto à luz da Constituição Federal [...]” (SANTA CATARINA, 2017, p. 357)

A citação acima transcrita revela, que pela norma jurídica aqui tratada, para além de entregar a prestação jurisdicional, a autoridade judicial exerceu a função social que dela se espera, pois: "É necessário que se incremente a postura hermenêutica do juiz no intuito de aproxima-lo dos ideais constitucionais". (CUBAS JÚNIOR; TEIXEIRA, 2017, p. 65-66)

Em arremate argumentativo lançado na sentença, verifica-se que a preocupação da autoridade judicial com a observância dos preceitos constitucionais se deve, também, à tentativa de garantir a permanência da Lei [Estatuto do Desarmamento] no sistema jurídico, 
dando-lhe o alcance exigido pela Carta Constitucional, porquanto sua aplicação irrestrita tenderia a macular, pelo vício de inconstitucionalidade, integralmente o texto legislado: "Só assim a Lei 10.826/03 pode ser considerada, em algum nível, compatível com o ordenamento constitucional e com os mais elementares princípios do direito natural que dão fundamento e sentido à Constituição em si.” (SANTA CATARINA, 2017, p. 359)

Ao buscar fundamentos no Texto Constitucional, entre eles as garantias fundamentais encartadas em Cláusulas Pétreas, a autoridade judicial tratou de conformar a norma jurídica [inserta na sentença] com o ordenamento jurídico pátrio, validando-a pela Constituição Federal [notadamente nos princípios por esta estabelecidos e cujas diretrizes/limites para a aplicação das leis destes derivam] e aproximando-a "da sociedade, quando em sua essência, alinham-se aos princípios constitucionais a consciência social do julgador”. (CUBAS JÚNIOR; TEIXEIRA, 2017, p. 74)

\section{CONSIDERAÇÕES FINAIS}

No curso da pesquisa foi possível observar que, para Ehrlich a sociologia é a verdadeira ciência do direito, porquanto este não é fruto de mera análise simplista do texto posto, da letra da lei. Antes, deve ser buscado no dia-a-dia do agir humano, não se encontra nos tribunais, nas decisões judiciais, mas emana da sociedade [organizações] como normas que, embora não positivadas [transformadas em prescrições jurídicas] são observadas independentemente de coação estatal oficial.

Assim, a obediência à norma decorre da coação inserta na própria organização da qual o homem participa, tal como a reprovação moral perante o grupo. Posicionando-se contrário ao monismo jurídico, Ehrlich admite que o direito não tem origem apenas no Estado, mas advém de fontes heterônomas e, por isso, defendia o pluralismo jurídico. $\mathrm{O}$ direito, admitido em sua concepção sociológica, impõe ao pesquisador a necessidade de observar a realidade social, o concreto, descrever os fatos e não se ater meramente em palavras. Não deve ser buscado na jurisprudência ou no produto final criado a partir da tarefa do legislador [processo legislativo], mas na observação da conduta humana, naquilo que o homem admite, aceita e cumpre como regra que lhe é imposta pela sociedade [e todas as organizações das quais faça parte], o que se denominou de Direito Vivo e no qual se funda a validade da norma.

De outro lado, para Kelsen, em sua Teoria Pura do Direito, há a necessidade de se depurar do conhecimento jurídico, notadamente da ciência do direito, quaisquer análises de 
externalidades, de tal maneira que para o direito a conduta humana só importaria na medida em que prescrita, positivada. Assim, pelo normativismo jurídico, o jurista deve partir da norma jurídica para chegar à norma jurídica, sem questionar valores axiológicos que antecedem sua elaboração e, por isso, a validade está ligada ao processo de sua formação, ou seja, se cumpriu as formalidades previstas no ordenamento jurídico, sem perquirir se ela é certa ou errada, se é eficaz ou ineficaz, de modo que, com o empírico, com o agir humano como ele é, a ciência do direito não deve se preocupar.

Com os pressupostos de validade da norma estabelecidos em cada teoria [cada autor], passou-se ao cotejo do caso concreto - uma norma jurídica [sentença] expedida por autoridade judicial - à luz dos referidos pressupostos, limitando-se o alcance da análise [pesquisa] à investigação dos fundamentos utilizados e se estes poderiam [ou não] justificar a conformação de validade da norma pela teoria do Direito Vivo e/ou pela Teoria Pura do Direito [normativismo jurídico].

Assim, extraídos determinados elementos que fundamentaram a sentença prolatada, entre eles a acentuada descrição da conduta humana exigível naquela comunidade em que o homem está inserido, os costumes locais e práticas habituais, os valores encartados em princípios e garantias fundamentais insculpidos na Constituição Federal, foi possível observar que, no caso concreto, a norma expedida encontra conformação de validade tanto no Direito Vivo quanto no normativismo jurídico, tanto em Ehrlich quanto em Kelsen, isolados ou conjuntamente.

Para a validade da norma jurídica, o que se vislumbra é a possibilidade de harmonizar as teorias desenvolvidas por Ehrlich e Kelsen, notadamente quando ela advém de autoridade judicial, em cuja tarefa judicante não nega vigência à lei, mas ao aplicá-la o faz nos limites exigíveis em razão da realidade social [observação do agir humano] e, especialmente, respeito pleno às garantias constitucionais [hierarquia das normas].

No caso em questão não se buscou [por não ser objeto do presente artigo] avaliar a correção ou não da interpretação dada pela autoridade judicial, mas em reconhecer que os argumentos e fundamentos utilizados para a expedição da norma permitem atrair, em sua leitura, as teorias aqui tratadas.

A despeito de não se confundir com o objeto do presente artigo, porquanto este limitado à análise do caso concreto sob a ótica da validade da norma em Ehrlich e Kelsen, não se pode negar que dúvidas emergem quanto à legalidade da atuação judicante em enveredar pelo caminho da observação do agir humano. Parece-nos, contudo, que essa discussão não se 
figura legítima se a validade da norma pode ser aferida, mesmo em Kelsen, a partir da interpretação das leis à luz dos Princípios Constitucionais, caso contrário, se essa é uma leitura que não se pode fazer pelo normativismo jurídico, haveria então de se dizer: "O Direito axiologicamente neutro, livre de subjetividade e os ideias de purificação do afazer jurídico, na esteira da doutrina Kelseniana, é um fato superado pela evolução filosófica e a própria complexidade das relações sociais". (CUBAS JÚNIOR; TEIXEIRA, 2017, p. 57).

\section{REFERÊNCIAS}

BARACHO, J.A.O. Aspectos da teoria de kelsen. In: Revista da Faculdade de Direito da Universidade Federal de Minas Gerais, Belo Horizonte: Imprenta, v. 27, n. 21, maio.1979, p. 9-50.

<https://www.direito.ufmg.br/revista/index.php/revista/article/download/823/768>. Acesso em 06.mar.2018.

CARLOTTI, D.P. O debate entre ehrlich e kelsen: a convergência filosófica entre positivismo jurídico e sociologia do direito no começo do século xx. In: Quaestio Iuris, Rio de Janeiro: v. 8, 2015, p. 2.287-2.303. Disponível em: <http://www.epublicacoes.uerj.br/index.php/quaestioiuris/article/download/20928/15309>. Acesso em 26.fev.2018.

CASTRO, J. R. Direito e modernidade: estudo sobre eugen ehrlich e hans kelsen. In: Convenit Internacional, São Paulo: USP, v. 22, set./dez/2016, p. 51-60. Disponível em <http://www.hottopos.com/convenit22/51-60Jonathas.pdf>. Acesso em 26.fev.2018.

CUBAS JÚNIOR, J. R.; TEIXEIRA, I. T. M. Leitura Crítica do Papel do Juiz no Processo Penal. In: COSTA, Margarete Terezinha de Andrade (Coord). Direito e Sociedade: o paradigma do acesso à justiça. Curitiba: Ponto Vital, 2017, p. 55-77.

CUNHA, R.A. Hermenêutica jurídica em kelsen: apontamentos críticos. In: Revista de Informação Legislativa, Brasília: Senado Federal, v. 180, out./dez.2008, p. 279-291. Disponível em <http://www2.senado.leg.br/bdsf/handle/id/176576>. Acesso em 26.fev. 2018.

EHRLICH, E. Fundamentos da sociologia do direito. Tradução de René Ernani Gertz, revisão de Vamireh Chacon. Brasília: UnB, 1986.

KELSEN, H. Teoria pura do direito. Tradução de João Baptista Machado. 8. ed. São Paulo: Martins Fontes, 2009.

LOSANO, M.G. O valor da justiça na obra de kelsen. In: Revista da Faculdade de Direito, Curitiba: UFPR, v. 59, n. 2, ago.2014, p. 31-45. Disponível em: <http://revistas.ufpr.br/direito/article/view/37561>. Acesso em 27.fev.2018.

MOREIRA, J.S. O método na sociologia do direito: ehrlich visitado por pachukanis. In: Revista Latinoamericana de Política, Filosofía y Derecho. Ciudad de México: Crítica Jurídica, 
n. 35, jan./jun.2013, p. 215-249. Disponível em: <http://www.revistas.unam.mx/index.php/rcj/article/view/40806>. Acesso em 05.fev. 2018.

SGARBOSSA, L. Reflexões ontológicas e epistemológicas sobre o campo jurídico. In: Revista da Faculdade de Direito - RFD, Rio de Janeiro: UERJ, n. 29, jun. 2016, p. 158-174. Disponível em: <http://www.e-publicacoes.uerj.br/index.php/rfduerj/article/view/14107>. Acesso em: 05.fev.2018.

SPAREMBERGER, R.F.L. A natureza da ciência jurídica: a polêmica entre o normativismo de hans kelsen e o sociologismo (hermenêutica do direito vivo) de eugen ehrlich. In: Revista Direito em Debate, Ijuí: Unijuí, v. 12, n. 20, jul./dez.2013, p. 115-135. Disponível em: <https://www.revistas.unijui.edu.br/index.php/revistadireitoemdebate/article/view/740>. Acesso em 05.fev. 2018.

VIEIRA, R.S. Pluralismo jurídico clássico: a contribuição de ehrlich, santi romano e gurvitch. In: Revista Direito, Estado e Sociedade, Rio de Janeiro: PUC-Rio, v. 47, jul./dez.2015, p. 108-127. Disponível em: <http://direitoestadosociedade.jur.pucrio.br/media/artigo05n47.pdf>. Acesso em 05.fev.2018.

SANTA CATARINA. Tribunal de Justiça. Vara Criminal da Comarca de Joaçaba. Ação Penal $n^{\circ}$ 0001455-21.2015.8.24.0037. Porte ilegal de arma de fogo. Autor: Ministério Público de Santa Catarina. Acusados: M.A.R., Y.V.Z., E.C.R. e F.S.M. Julgador: Juiz de Direito Marcio Humberto Bragaglia. Joaçaba, 18 jan. 2018. Diário da Justiça Eletrônico [DJe] 17 jan. 2018, n. 2739, p. 458-459. Disponível em <http://busca.tjsc.jus.br/djeconsulta/rest/diario/caderno?edicao=2739\&cdCaderno=3> . Acesso em 26 jun. 2018 